nanoparticles have been observed to cause lung parenchyma inflammation and granuloma formation in an animal model. ${ }^{5}$

Conclusions: Kaolinite mineral capacity for adsorption of heavy metals, in particular cadmium, could explain the scale and pattern of Caplan's syndrome incidence seen in Welsh coal miners and Cornish kaolin workers, and further explains the interactive risk seen in sequential dust and cigarette smoke exposure. References:

[1] Morton J, Tan E, Leese E, Cocker J. Determination of 61 elements in urine samples collected from a non-occupationally exposed UK adult population. Toxicol Lett. 2014;231(2):179-93.

[2] Wells IP, Bhatt RC, Flanagan M. Kaolinosis: a radiological review. Clin Radiol. 1985;36(6):579-82.

[3] Bonglaisin JN, Mbofung CMF, Lantum DN. Intake of Lead, Cadmium and Mercury in Kaolin-eating: A Quality Assessment. J Med Sci 2011;11(7):267273.

[4] Song D, Wang M, Zhang J, Zheng C. Contents and occurrence of cadmium in the coals from Guizhou province, China. Ann N Y Acad Sci. 2008;1140:274-81.

[5] Coccini T, Barni S, Vaccarone R, et al. Pulmonary toxicity of instilled cadmiumdoped silica nanoparticles during acute and subacute stages in rats. Histol Histopathol. 2013 1;28(2):195-209.

Acknowledgements: Cornwall Arthritis Trust.

Disclosure of Interest: None declared

DOI: 10.1136/annrheumdis-2017-eular.3727

\section{AB0307 DIFFERENTIAL ASSOCIATION OF AGE AND DISEASE ACTIVITY WITH CAROTID INTIMA-MEDIA THICKNESS IN MEN AND WOMEN WITH RHEUMATOID ARTHRITIS}

D. Taverner $^{1}$, S. Paredes ${ }^{1}$, R. Ferre ${ }^{2}$, L. Masana ${ }^{2}$, A. Castro ${ }^{2}$, J.C. Vallve ${ }^{3}$. ${ }^{1}$ Rheumatology; ${ }^{2}$ Internal Medicine; ${ }^{3}$ Biologyst, Hospital Sant Joan de Reus, Reus, Spain

Background: Rheumatoid arthritis (RA) is the most common chronic inflammatory condition and is characterized by an increase risk in cardiovascular (CV) disease. Carotid intima-media thickness (CIMT) is a surrogate marker of CV disease and many studies have evaluated the relationship between CIMT and RA disease activity with contradictory results.

Objectives: To evaluate in RA patients the association between both cIMT and carotid plaque presence and clinical RA features and analytical measurements. Methods: We selected 214 RA patients according to the American College of Rheumatology criteria. Conventional clinical evaluation and analytical measurements were performed, including a standard lipid profile. We used My Lab 50 $\mathrm{X}$-Vision sonograph to measure cIMT and atherosclerotic plaque presence Results: No differences between men and women regarding age, body mass index, glycaemia, LDL-C and TG were observed. However, men had a significantly higher waist circumference, systolic and diastolic BP and lower levels of HDLc. On the other hand, women had significantly higher values of DAS28 (3.7 vs 2.99), $\mathrm{HAQ}$, and VSG with no differences in other inflammatory variables (rheumatoid factor, ACPA, CRP or fibrinogen). Moreover, $74 \%$ of patients had pathological cIMT without gender differences and $43 \%$ had plaque presence in the carotid artery with a significant higher percentage in men (57\%) than women (36\%). Overall, men had significantly higher cIMT ( 0.678 vs $0.627 \mathrm{~mm})$ but when disease activity (DAS28) was considered, we observed that such difference was due to patients that were in remission or in low activity. Men and women with moderate and high disease activity had no statistical differences in cIMT. Furthermore, across women cIMT was significantly higher in those with high disease activity compared with remission. This effect was not observed in men. Multivariate linear regression with cIMT showed a significant interaction between age and gender, so that the effect of age on cIMT was significantly more pronounced in men than in women. Conclusions: We have described that in our RA cohort, disease activity measured with DAS28 and age are differentially associated with cIMT in men and women. Our results could explain the contradictory results published in the literature and it can be justified by a higher incidence of RA in women and by the hormonal-genetic status.

Disclosure of Interest: None declared

DOI: 10.1136/annrheumdis-2017-eular.2704

\section{AB0308 DISEASE ACTIVITY, GRIP STRENGTHS AND HAND DEXTERITY IN PATIENTS WITH RHEUMATOID ARTHRITIS}

D. Palamar ${ }^{1}$, G. $\mathrm{Er}^{1}$, R. Terlemez ${ }^{1}$, U. Isil ${ }^{2}, \mathrm{G}_{\text {. }} \mathrm{Can}^{3}$, M. Saridogan ${ }^{1}$. ${ }^{1}$ Department of Physical Medicine and Rehabilitation, Istanbul University Cerrahpasa Medical Faculty; ${ }^{2}$ Physical Medicine and Rehabilitation Clinic, Bagcilar Training Hospital; ${ }^{3}$ Department of Public Health, Istanbul University Cerrahpasa Medical Faculty, Istanbul, Turkey

Background: Rheumatoid arthritis (RA) is a chronic inflammatory disease affecting hand joints, and leading impairment in hand functions. To date many scientific studies assessed the disease activity of patients with RA, but little attention has been carried out to assess hand functions, and dexterity (1-2).

Objectives: The purpose of this study was to determine the clinical relevance of the Quick Disabilities of Arm, Shoulder and Hand (QuickDASH), hand dexterity with the Purdue Pegboard Test (PPT), and grip and pinch strengths of RA patients.
Methods: Eighty-two women with a diagnosis of RA according to the 2010 American College of Rheumatology/the European League Against Rheumatism (ACR/EULAR) criterion were recruited to the study. The disease activity scores were determined by using Disease activity score-28 (DAS-28). Grip strengths was measured with a Jamar dynamometer, and pinch strengths were measured by pinchmeter. Hand functions were evaluated with the PPT, and functional outcomes were assessed with the QuickDASH questionnaire.

Results: The mean age of the study group was $49.27 \pm 10.69$ years. Average values of DAS-28, the QuickDASH values were found to be $4.22 \pm 1.28$, $38.33 \pm 19.78$, consecutively. High correlation was observed between DAS-28 and the QuickDASH values $(p<0.001)$. The mean grip strengths were significantly correlated with the QuickDASH and DAS-28 values $(p<0.01)$ (Table 1$)$. The mean lateral pinch strengths were correlated significantly with DAS-28 and the QuickDASH scores $(p<0.001)$. DAS-28 was correlated with PPT performance just on the dominant hand $(p<0.05)$. The QuickDASH values were not correlated with all PPT performances $(p>0.05)$. Grip strengths were positively correlated with the PPT performances $(p<0.05)$.

Table 1. Showing the correlation coefficients of DAS 28 and QuickDASH scores between other parameters

\begin{tabular}{|c|c|c|}
\hline & \multicolumn{2}{|c|}{ Correlation coefficients $(r)$} \\
\hline & DAS 28 & QuickDASH \\
\hline QuickDASH & $0.616^{\star \star \star}$ & \\
\hline Grip strength (dominant hand) & $-0.412^{\star \star \star}$ & $-0.409^{\star \star \star}$ \\
\hline Grip strength (nondominant hand) & $-0.329^{\star \star}$ & $-0.404^{\star \star \star}$ \\
\hline Lateral pinch strength (dominant hand) & $-0.320^{\star \star \star}$ & $-0.327^{\star \star \star}$ \\
\hline Lateral pinch strength (nondominant hand) & $-0.276^{\star}$ & $-0.310^{\star \star}$ \\
\hline Palmar pinch strength (dominant hand) & -0.215 & -0.157 \\
\hline Palmar pinch strength (nondominant hand) & -0.190 & -0.165 \\
\hline Tip pinch strength (dominant hand) & $-0.248^{\star}$ & $-0.237^{\star}$ \\
\hline Tip pinch strength (nondominant hand) & $-0.227^{\star}$ & -0.201 \\
\hline Dexterity (dominant hand) & $-0.277^{\star}$ & -0.033 \\
\hline Dexterity (nondominant hand) & -0.128 & -0.098 \\
\hline Dexterity (both hands) & 0.004 & 0.059 \\
\hline Dexterity (assembly) & -0.084 & 0.047 \\
\hline
\end{tabular}

Conclusions: In conclusion, we determined that grip strengths were significantly related to disability and disease activity in RA patients in our study. The clinical significance of QuickDASH is high, and the questionnaire can be used effectively. References:

[1] Aktekin LA, Eser F, Baskan BM, et al. Disability of Arm Shoulder and Hand Questionnaire in rheumatoid arthritis patients: relationship with disease activity, HAQ, SF-36. Rheumatol Int.2011;31:823-6.

[2] Singh $H$, Kumar $S$, Talapatra $P$, et al. Assessment of hand functions in rheumatoid arthritis using SF-SACRAH (short form score for the assessment and quantification of chronic rheumatoid affections of the hands) and its correlation to disease activity. Rheumatol Int. 2012;32:3413-9.

Disclosure of Interest: None declared

DOI: 10.1136/annrheumdis-2017-eular.3541

\section{AB0309 LIPID-LOWERING INTERVENTION OF A PREVENTIVE CARDIO-RHEUMA CLINIC IN MEXICAN MESTIZO PATIENTS WITH RHEUMATOID ARTHRITIS}

D.Á. Galarza-Delgado ${ }^{1}$, J.R. Azpiri-López ${ }^{2}$, I.J. Colunga-Pedraza ${ }^{1}$,

R.E. Ramos-Cázares ${ }^{1}$, F.J. Torres-Quintanilla ${ }^{2}$, A. Valdovinos-Bañuelos ${ }^{1}$,

R.I. Arvizu-Rivera ${ }^{3}$, A. Martínez-Moreno $^{3}$, J.A. Cárdenas-de la Garza ${ }^{3}$,

R. Vera-Pineda ${ }^{3}$, J. García-Colunga ${ }^{4}$, M.A. Garza-Elizondo ${ }^{1}$,

G. Elizondo-Riojas ${ }^{4} .{ }^{1}$ Rheumatology; ${ }^{2}$ Cardiology; ${ }^{3}$ Internal Medicine;

${ }^{4}$ Radiology, Universidad Autónoma de Nuevo León, Monterrey, Mexico

Background: Patients with rheumatoid arthritis (RA) have a significantly increased risk for cardiovascular $(\mathrm{CV})$ morbidity and mortality when compared to general population (1). Preventive cardio-rheuma clinics have been created in recent years and proven to be effective to manage $\mathrm{CV}$ risk in patients with inflammatory joint diseases around the world (2).

Objectives: To evaluate the need for lipid-lowering intervention in Mexican mestizo patients with RA.

Methods: We initiated a preventive cardio-rheuma clinic for appropriate CV disease prevention in patients with RA in our population. A complete evaluation and CV risk stratification was performed to our patients, including blood tests and ultrasound examination of both carotid arteries. Each patient was classified to lifestyle changes only, a lifestyle intervention plus lipid-lowering treatment, or to have a low risk with no need for intervention, in accordance to the 2012 European Guidelines on cardiovascular disease prevention in clinical practice and the 2016 ESC/EAS Guidelines for the Management of Dyslipidemias.

Results: A total of 100 patients were evaluated, patient characteristics and intervention group distribution are shown in Table 1. Among these patients, 49 were found not to need any lipid-lowering intervention. The remaining 51 were classified into lifestyle change $(n=18,35.3 \%)$ or lipid-lowering drug regimens $(n=33,64.7 \%)$. A significant difference between intervention groups was only found regarding age $(p<0.001)$. A multiple regression analysis was performed to predict the kind of intervention needed from age, disease duration, disease 